\title{
Quinoline-2-thiol Derivatives as Fluorescent Sensors for Metals, pH and HNO
}

\author{
Naphtali A. O’Connor*, Gustavo E. López and Anthony Cruz
}

Department of Chemistry, Lehman College City University of New York, 250 Bedford Park Blvd West, NY 10468, USA

\begin{tabular}{l}
\hline C H R O N I C L E \\
\hline Article history: \\
Received January 22, 2014 \\
Received in revised form \\
February 02, 2014 \\
Accepted 6 March 2014 \\
Available online \\
7 March 2014 \\
\hline Keywords: \\
HNO \\
Fluorescent sensor \\
pH probe \\
Metal probe \\
Pyridine-2-thiol
\end{tabular}

\begin{tabular}{l} 
A B S T R A C T \\
\hline A tautomeric equilibrium exists for quinoline-2-thiol and quinoline- $2(1 H)$-thione. Quantum \\
mechanical calculations predict the thione is the major tautomer and this is confirmed by the \\
absorption spectra. The utility of quinolone-2-thiol/quinoline- $2(1 \mathrm{H})$-thione as a chromophore \\
for developing fluorescent sensors is explored. No fluorescence is observed when excited at \\
absorption maxima, however a fluorescence increase is observed when exposed to HNO, a \\
molecule of import as a cardiovascular therapeutic. Alkylated quinoline-2-thiol derivatives are \\
found to be fluorescent and show a reduction in fluorescence when exposed to metals and \\
changes in $\mathrm{pH}$.
\end{tabular}

() 2014 Growing Science Ltd. All rights reserved.

\section{Introduction}

Thiols are uniquely versatile, displaying a wide variety of chemistry including being nucleophilic, acidic, metal coordinative and redox reactive. As such they are uniquely positioned to be the platform from which versatile fluorescent sensors can be developed. Sulfur based functional groups have been utilized as fluorescent sensors, particularly as metal sensors. For example, thiols and related functional groups are widely utilized as selective metal chelators and have been reported as fluorescent chemosensors for metals such as $\mathrm{Hg}^{2+}, \mathrm{Ag}^{+}$, and $\mathrm{Cu}^{2+}$ ions. ${ }^{1-4}$ These metal sensors take advantage of fluorescence quenching by sulfur via photoinduced electron transfer (PET).

Thiols are also sensitive to oxidizing agents and electrophilic species and therefore offer versatility for developing fluorescent probes. Nitrogen oxide $\left(\mathrm{NO}^{\circ}\right)$ and its derivatives have recently come under scrutiny because of their importance in biological function and recent connections with diseases. $\mathrm{NO}^{\circ}$ is important for signaling and immune response in humans. ${ }^{5,6}$ Over-production of NO has been linked to cancer, chronic inflammatory diseases and neurodegenerative diseases. The nitroxyl anion $\mathrm{NO}^{-}$resulting from the reduction of $\mathrm{NO}^{\circ}$ has received recent attention for its biological function and for its potential therapeutic application against cardiovascular diseases. ${ }^{7}$ At 
physiological $\mathrm{pH}$ the protonated species $\mathrm{HNO}$ predominates. HNO can be detected indirectly by measuring $\mathrm{N}_{2} \mathrm{O}$, the reductive nitrosylation of oxidized metal complexes or observing the reaction products of thiols. ${ }^{8}$ Now a molecule of great import, fluorescent sensors for HNO have only been recently developed. One strategy relies on the reduction of a $\mathrm{Cu}^{2+}$ complex by HNO. ${ }^{9,10}$ Another recent strategy has been to utilize a nonfluorescent TEMPO derivative that reacts with HNO and becomes fluorescent. ${ }^{11}$ Thiols react with HNO to produce sulfinamides and disulfides and are well situated to produce fluorescent sensors for the important molecule.

Pyridine-2-thiol is of interest as a sensing functionality as it is well known to form metal complexes with transition metals including mercury ${ }^{12}$, silver ${ }^{13}$ and copper ${ }^{14,15}$. Additionally the deprotonation of the thiol and protonation of the pyridine functionalities can allow it to act as a $\mathrm{pH}$ probe. However a tautomeric equilibrium exists between pyridine-2-thiol and pyridine- $2(1 H)$-thione, and though studied heavily, there are conflicting reports about the identity of the major tautomer. ${ }^{16}$ The effect a pyridyl-2-thiol subunit and its tautomerization on the fluorescence properties of a larger conjugated system is unknown. To study the effect of the pyridyl-2-thiol/thione functionality on fluorescence, quinolone-2-thiol/thione 1a-b is examined. Evidence suggests the major tautomer is the thione $\mathbf{1 b}$ and that it is non-fluorescent. The utility of the pyridine-2-thiol functionality as a sensing unit is displayed by using quinoline-2-thiol and derivatives 2-3 as fluorescent probes for heavy metals, $\mathrm{pH}$ and HNO.

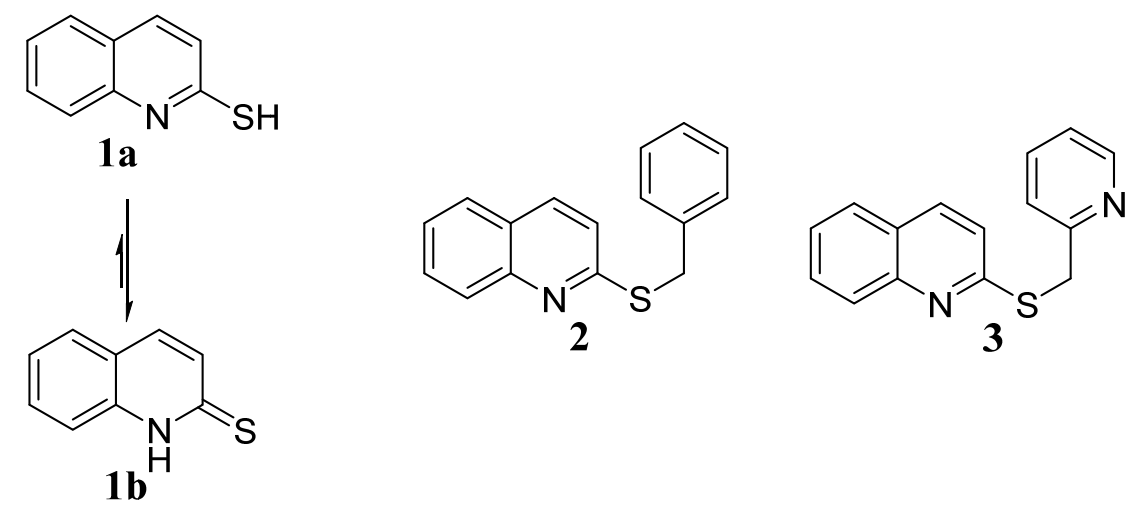

Fig. 1. Quinoline thiol derivatives 1-3

\section{Results and Discussion}

A tautomeric equilibration exists for quinoline-2-thiol/quinoline-2(1H)-thione (1a-b) and the favoured tautomer is responsible for the shape of the absorption spectrum. The identity of the major tautomer in the quinoline-2-thiol/quinoline-2(1H)-thione equilibrium was confirmed by a B3LYP DFT computation of the relative populations that showed the thione favoured at $99.9 \%$ with $\Delta \mathrm{E}=$ $5.83 \mathrm{kcal} / \mathrm{mol}$. This was confirmed by a TD-DFT computation of the absorption spectra of the tautomers. The thione 1b calculated spectrum shows strong bands at $358.8 \mathrm{~nm}\left(\mathrm{~S}_{2}\right)$ and $269.8 \mathrm{~nm}\left(\mathrm{~S}_{5}\right)$ and matches well with the experimentally obtained spectrum with strong bands at $372 \mathrm{~nm}$ and 273 $\mathrm{nm}$ in $\mathrm{H}_{2} \mathrm{O}$ (Figure 2). The calculated thiol 1a has strong bands at $308.0 \mathrm{~nm}\left(\mathrm{~S}_{1}\right)$ and $242.9 \mathrm{~nm}\left(\mathrm{~S}_{4}\right)$ and occurs in regions of low thione absorption. When excited at the UV/vis absorption maxima for both transitions, no fluorescence is observed and it is confirmed that the thione $\mathbf{1 b}$ is non-fluorescent. 

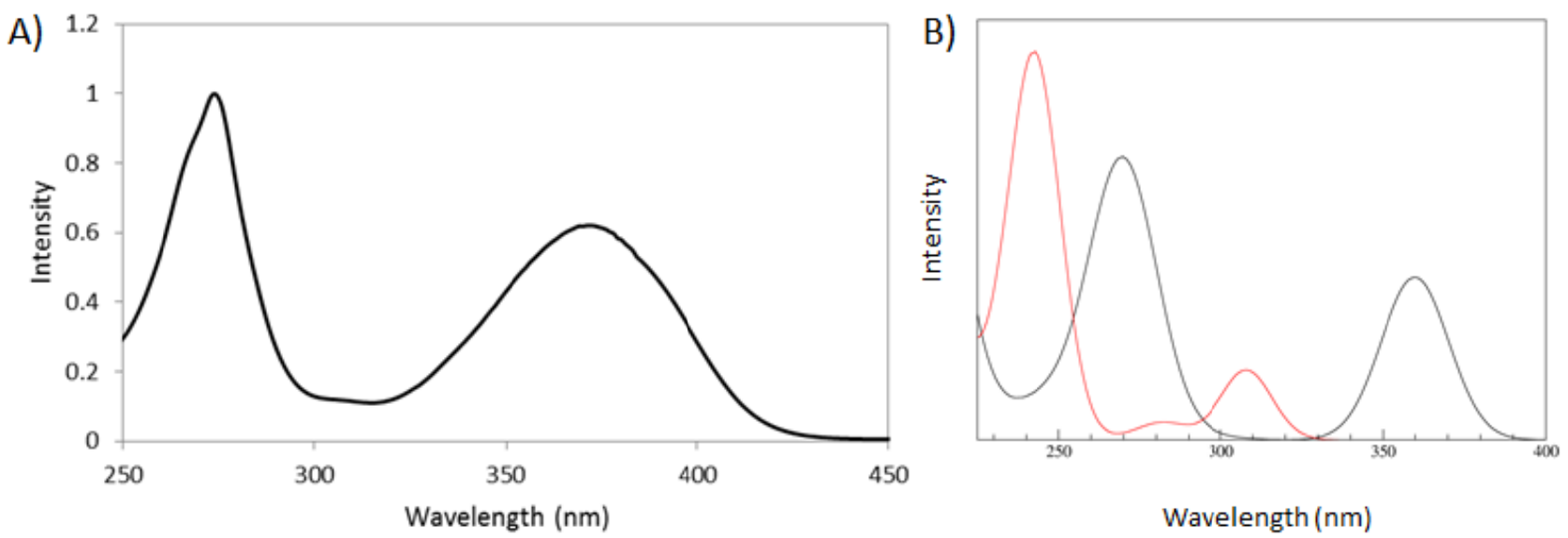

Fig. 2. a) UV/Vis absorption of $\mathbf{1}\left(10^{-4} \mathrm{M} \mathrm{H}_{2} \mathrm{O}\right)$; b) TD-DFT calculated spectra ( — quinoline-2-thiol, - quinoline-2(1H)-thione).

Table 1. Singlet transition energies and oscillator strength for Quinoline-2-thiol and Quinoline$2(1 H)$-thione

\section{Quinoline-2(1H)-thione}

State (Cs)

$\mathrm{S}_{2}\left({ }^{1} \mathrm{~A}\right)$

$\mathrm{S}_{5}\left({ }^{1} \mathrm{~A}\right)$

Quinoline-2-thiol
$\mathrm{S}_{1}\left({ }^{1} \mathrm{~A}\right)$

$\mathrm{S}_{2}\left({ }^{1} \mathrm{~A}\right)$

$\mathrm{S}_{4}\left({ }^{1} \mathrm{~A}\right)$
Singlet transition energies (nm)

358.84

269.75

308.01

282.01

242.86
Oscillator strength

0.3100

0.5317

HNO shows great thiol reactivity as opposed to $\mathrm{NO}^{\circ}$ and reacts with thiols to generate sulfinamides or disulfides. ${ }^{17}$ The detection of thiol modification by mass spectrometry is a method for determining the presence of HNO. Thiol reactivity with HNO can also be exploited for detection by fluorometric means and it is surmised that quinoline-2-thiol/thione can act as a prototype for fluorescent sensors for HNO. Exposure of quinoline-2-thiol/thione to HNO resulted in a fluorescence response, while being unresponsive to direct exposure to $\mathrm{NO}^{\circ}$ via DEA-NONOate degradation. Figure 3 shows quinoline-2-thiol/thione exhibiting a fluorescence response to $\mathrm{HNO}$ when exposed to 100 equivalents of Angeli's salt $\left(\mathrm{Na}_{2} \mathrm{~N}_{2} \mathrm{O}_{3}\right)$. The increase continued for 40 minutes after which it became stabilized. The resulting florescence from reaction with HNO did not match that of the disulfide and is concluded to result from the sulfinamide.

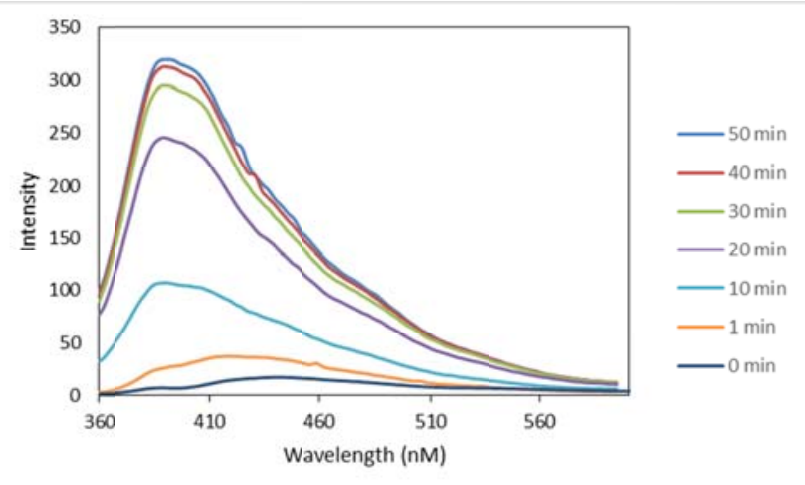

Fig. 3. $10^{-4} \mathrm{M} 1$ in $\mathrm{H}_{2} \mathrm{O}$ with 100 equivalents of Angeli's salt $\left(\lambda_{\text {excit }} 340 \mathrm{~nm}\right)$. 
Unlike quinolone-2-thiol/thione, derivatives 2-3 are fluorescent and show a response to changes in $\mathrm{pH}$ and metals. Derivatives 2 and $\mathbf{3}$ showed decreases in fluorescence between $\mathrm{pH} 3$ and 4 when titrated from basic to acidic $\mathrm{pH}$ (Figure 4a). This fluorescence decrease coincides with the protonation of the quinoline nitrogen. A $>5$ fold change in fluorescence was seen for 2 and a $>10$ fold was seen for 3. Heavy metals are known to form complexes with pyridine-2-thiol and therefore compounds 1-3 were titrated with metal ions to examine their effect on fluorescence. Thiol/thione 1 shows a fluorescence response to metals but this was found to be dependent on the metal's counterion. For example, 1 produces a fluorescent metal complex in the presence of $\mathrm{CuBr}_{2}$ and $\mathrm{CuCl}_{2}\left(\lambda_{\text {em }}\right.$ $425,685 \mathrm{~nm}$ respectively) but not in the presence of $\mathrm{CuSO}_{4}$ and $\mathrm{Cu}(\mathrm{OAc})_{2}$. Reaction of pyridine-2thiol and $\mathrm{Cu}^{2+}$ ions results in the formation of various copper complexes and some oxidation to the disulfide. $^{18,19}$ Analysis of the transformation of $\mathbf{1}$ on introduction of $\mathrm{Cu}^{2+}$ showed the oxidation product disulfide, which was confirmed by NMR and direct oxidation to form the disulfide with $\mathrm{NaIO}_{4}$. Therefore the pyridyl-2-thiol functionality is not practical for fluorescent metal probes as their response is metal complex specific. Efforts to isolate the fluorescent species have proven difficult as the reaction results in a complex mixture. Alkylated quinolone-2-thiol derivatives $\mathbf{2}$ and $\mathbf{3}$ were in contrast observed to be fluorescent and titration with various heavy metals resulted in the quenching of fluorescence. Quinoline-2-thiol derivatives 2 and 3 have a $\lambda_{\text {em }}$ of $380 \mathrm{~nm}$ and diminished fluorescence is observed in the presence of $\mathrm{CrCl}_{3}, \mathrm{CuSO}_{4}, \mathrm{FeCl}_{2}$ and $\mathrm{FeCl}_{3}$ (Figure $4 \mathrm{~b}$ ). The turning off of fluorescence is immediate and steady, indicating quenching is due to chelation and not resultant from downstream reactions as in the case of quinoline-2-thiol. To support this, the decrease in fluorescence was observed to be reversible by adding the strong chelator EDTA. Changing the sulphide appendage from a pyridyl to a phenyl shows no changes, so all selectivity is determined by the quinoline sulphide functional group.
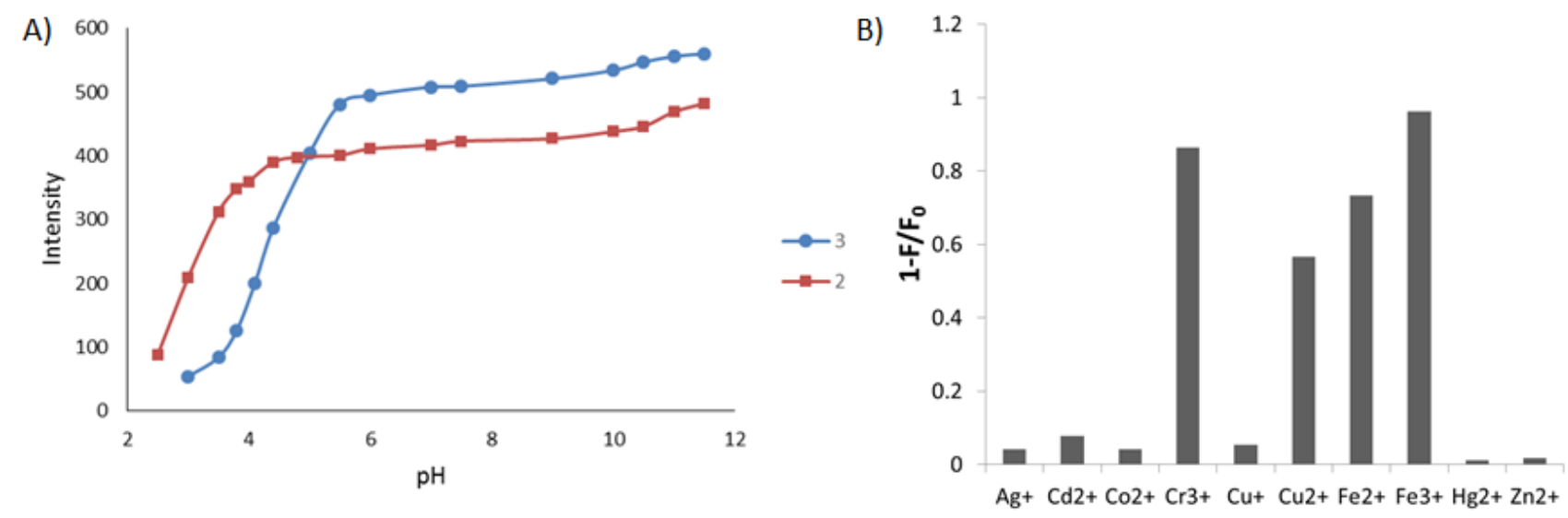

Fig. 4. a) $\mathrm{pH}$ titration curve of $10^{-5} \mathrm{M} 2$ and 3 in $0.01 \mathrm{M} \mathrm{NaOH}$ with $0.1 \mathrm{M} \mathrm{HCl}\left(\lambda_{\text {excit }} 340 \mathrm{~nm}\right)$ at 380 $\mathrm{nm}$. b) Fluorescence change $\left(\mathrm{F}_{0}=\right.$ initial, $\mathrm{F}=$ final $)$ of $10^{-5} \mathrm{M} 3$ in acetonitrile and 10 equivalents of $0.01 \mathrm{M}$ aqueous metal solutions $\left(\lambda_{\mathrm{ex}} 340 \mathrm{~nm}\right)$.

\section{Conclusions}

The pyridyl-2-thiol functionality displays a broad array of chemistry and therefore can be utilized to develop fluorescent sensors for metals, $\mathrm{pH}$ and HNO. The reaction of quinoline-2-thiol/thione with the HNO to create a fluorescent species shows a simple approach to develop sensors for this molecule of growing import. Alkylation of quinoline-2-thiol results in fluorescent molecules that are respondent to $\mathrm{pH}$ and metals.

\section{Experimental}

4.1. Materials and Methods. Quinoline-2-thiol was purchased from Sigma Aldrich. Angeli's salt, 1,1Diethyl-2-hydroxy-2-nitroso-hydrazine (DEA-NONOate) and all other reagents where purchased from Fisher Scientific. Compounds $\mathbf{2}$ and $\mathbf{3}$ were prepared as previously reported. ${ }^{20,21}$ 
4.2. Fluorescence titration experiments. Fluorescence measurements were performed on a Perkin Elmer LS55. For metal titration experiments, $10^{-5} \mathrm{M}$ quinoline thiol derivatives in acetonitrile titrated with 10 equivalents of $0.01 \mathrm{M}$ aqueous metal solutions. Metals used were $\mathrm{AgNO}_{3}, \mathrm{CdCl}_{2}, \mathrm{COCl}_{2}$, $\mathrm{HgCl}_{2}, \mathrm{CrCl}_{3}, \mathrm{CuOAc}, \mathrm{CuSO}_{4}, \mathrm{FeCl}_{2}, \mathrm{FeCl}_{3}$ and $\mathrm{ZnSO}_{4}$. $\mathrm{HNO}$ obtained by the degradation of Angeli's salt. A $10^{-4} \mathrm{M}$ solution of 1 in $\mathrm{H}_{2} \mathrm{O}$ was mixed with 100 equivalents of a $0.01 \mathrm{M}$ Angeli's salt solution. $\mathrm{pH}$ titrations performed with $10^{-4} \mathrm{M}$ solutions of quinoline thiol derivatives in $0.01 \mathrm{M}$ $\mathrm{NaOH}$ and $0.1 \mathrm{M} \mathrm{HCl}$ solutions.

4.3. Computational Studies. The method used in this study was based on ab-initio techniques within the density functional approximation. Specifically, the nonlocal Becke exchange coupled to the LeeYang-Parr gradient corrected correlation functional (B3LYP) was used with the cc-pVQZ basis set (B3LYP/cc-pVQZ level). For both systems a full geometry optimization was performed using Gaussian 03 software package ${ }^{22}$. Harmonic vibrational analysis was performed on both systems to ensure that a minimum in the potential energy surface was obtained. Vibrational and rotational temperatures were also computed and used in the calculation of the molecular partitions functions.

The fraction of tautomer $i, X_{i}$, at $\mathrm{T}=300 \mathrm{~K}$ was computed from $X_{i}=\frac{Q_{i}}{Q_{j}} e^{-\frac{\Delta E}{R T}}$, where $\mathrm{Q}_{\mathrm{i}}$ and $\mathrm{Q}_{\mathrm{j}}$ are the partition functions for tautomers $i$ and $j$, respectively, $\mathrm{R}$ is the ideal gas constant, and $\Delta \mathrm{E}$ is the difference in energy between tautomers $i$ and $j$. The absorption spectra for each tautomer was computed using time-dependent density functional theory, i.e. B3LYP-TD/cc-pVQZ level, coupled to the polarizable continuum model using the integral equation formalism variant (IEFPCM).

\section{References}

1 Chae M. Y., and Czarnik A. W. (1992) Fluorometric chemodosimetry. Mercury(II) and silver(I) indication in water via enhanced fluorescence signaling. J. Am. Chem. Soc., 114(24), 9704-9705.

2 Liu B., and Tian H. (2005) A selective fluorescent ratiometric chemodosimeter for mercury ion. Chem. Commun., 25), 3156-3158.

3 Kim H. J., Lee S. J., Park S. Y., Jung J. H., and Kim J. S. (2008) Detection of cuii by a chemodosimeter-functionalized monolayer on mesoporous silica. Adv. Mater., 20(17), 3229-3234.

4 Saleh N. I. (2009) Luminescent sensor for $\mathrm{Cd}^{2+}, \mathrm{Hg}^{2+}$ and $\mathrm{Ag}^{+}$in water based on a sulphurcontaining receptor: Quantitative binding-softness relationship. Luminescence, 24(1), 30-34.

5 Kvietys P. R., and Granger D. N. (2012) Role of reactive oxygen and nitrogen species in the vascular responses to inflammation. Free Radical Biol. Med., 52, 556-592.

6 Ramalingam M., and Kim S.-J. (2012) Reactive oxygen/nitrogen species and their functional correlations in neurodegenerative diseases. J. Neural Transm., 119, 891-910.

7 Irvine J. C., Ritchie R. H., Favaloro J. L., Andrews K. L., Widdop R. E., and Kemp-Harper B. K. (2008) Nitroxyl (HNO): The cinderella of the nitric oxide story. Trends Pharmacol. Sci., 29(12), 601-608.

8 Donzelli S., Espey M. G., Thomas D. D., Mancardi D., Tocchetti C. G., Ridnour L. A., Paolocci N., King S. B., Miranda K. M., Lazzarino G., Fukuto J. M., and Wink D. A. (2006) Discriminating formation of hno from other reactive nitrogen oxide species. Free Radical Biol. Med., 40(6), 1056-1066.

9 Rosenthal J., and Lippard S. J. (2010) Direct detection of nitroxyl in aqueous solution using a tripodal copper(II) bodipy complex. J. Am. Chem. Soc., 132(16), 5536-5537.

10 Royzen M., Wilson J. J., and Lippard S. J. (2013) Physical and structural properties of $[\mathrm{Cu}(\mathrm{BOT} 1) \mathrm{Cl}] \mathrm{Cl}$, a fluorescent imaging probe for hno. J. Inorg. Biochem., 118(162-170.

11 Cline M. R., and Toscano J. P. (2011) Detection of nitroxyl (HNO) by a prefluorescent probe. J. Phys. Org. Chem. 24(10), 993-998.

12 Lobana T. S., Sharma R., and Butcher R. J. (2008) Pyridine-2-thione (Pysh) derivatives of 
silver(I): Synthesis and crystal structures of dinuclear $\left[\mathrm{Ag}_{2} \mathrm{Cl}_{2}(\mu-\mathrm{s}-\mathrm{Pysh})_{2}\left(\mathrm{PPh}_{3}\right)_{2}\right]$ and $\left[\mathrm{Ag}_{2} \mathrm{Br}_{2}(\mu-\right.$ s-Pysh $)_{2}\left(\mathrm{PPh}_{3}\right)_{2}$ ] complexes. Polyhedron, 27(5), 1375-1380.

13 Su W., Hong M., Weng J., Liang Y., Zhao Y., Cao R., Zhou Z., and Chan A. S. C. (2002) Tunable polymerization of silver complexes with organosulfur ligand: Counterions effect, solvent- and temperature-dependence in the formation of silver(I)-thiolate(and/or thione) complexes. Inorg. Chim. Acta, 331(1), 8-15.

14 Constable E. C., Elder S. M., Palmer C. A., Raithby P. R., and Tocher D. A. (1996) Morphological variation in self-assembled copper(I) paddle-wheel complexes. Inorg. Chim. Acta, 252(1-2), 281291.

15 Evans I. P., and Wilkinson G. (1974) Complexes of pyridine-2-thiol with some transition metals. $J$. Chem. Soc. Dalton Trans., 946-951.

16 Moran D., Sukcharoenphon K., Puchta R., Schaefer H. F., 3rd, Schleyer P. V., and Hoff C. D. (2002) 2-pyridinethiol/2-pyridinethione tautomeric equilibrium. A comparative experimental and computational study. J. Org. Chem., 67(25), 9061-9069.

17 Donzelli S., Espey M. G., Thomas D. D., Mancardi D., Tocchetti C. G., Ridnour L. A., Paolocci N., King S. B., Miranda K. M., Lazzarino G., Fukuto J. M., and Wink D. A. (2006) Discriminating formation of hno from other reactive nitrogen oxide species. Free Radical Biol. Med., 40(6), 1056-1066.

18 Jeannin S., Jeannin Y., and Lavigne G. (1979) Unusual sulfur insertion in a copper(I)mercaptobenzothiazole complex: Synthesis and structural study of $\left[\mathrm{CuI}\left(\mathrm{C}_{7} \mathrm{H}_{5} \mathrm{NS}_{2}\right)\left(\mathrm{C}_{14} \mathrm{H}_{8} \mathrm{~N}_{2} \mathrm{~S}_{5}\right)\right]\left(\mathrm{ClO}_{4}\right) \cdot 2 \mathrm{CHCl}_{3}$. Inorg. Chem., 18(12), 3528-3535.

19 Ainscough E. W., Baker E. N., Bingham A. G., Brodie A. M., and Smith C. A. (1989) Interaction of Benzo-I,3-thiazoline-2-thione and related ligands with Copper(II) salts and the single-crystal $\mathrm{X}$-Ray structure of $\mathrm{p}$-[I ,2-bis-(dipheny1phosphino)ethanel-bis $\{($ benzo-I,3-thiazole-Z-thiolatoS)[I,2-bis(diphenylphosphinoethane]copper(I)\}. J. Chem. Soc. Dalton Trans., 2167-2170.

20 Ota M., Yanagisawa I., Takeuchi M., Shikama H., and Takagi T. (1987) Preparation of 2pyridylmethylthio- or 2-pyridylmethylsulfinyl-substituted cyclic compounds for preventing or treating gastropathy. Yamanouchi Pharmaceutical Co., Ltd., Japan.

21 Nakamura S., Furutani A., and Toru T. (2002) Highly enantioselective reaction of $\alpha$-lithio 2quinolyl sulfide using chiral bis(oxazoline)s: A new synthesis of enantioenriched thiols. Eur. $J$. Org. Chem., 1690-1695.

22 Frisch M. J. T., G. W.; Schlegel, H. B.; Scuseria, G. E.; Robb, M. A.; Cheeseman, J. R.; Montgomery, Jr., J. A.; Vreven, T.; Kudin, K. N.; Burant, J. C.; Millam, J. M.; Iyengar, S. S.; Tomasi, J.; Barone, V.; Mennucci, B.; Cossi, M.; Scalmani, G.; Rega, N.; Petersson, G. A.; Nakatsuji, H.; Hada, M.; Ehara, M.; Toyota, K.; Fukuda, R.; Hasegawa, J.; Ishida, M.; Nakajima, T.; Honda, Y.; Kitao, O.; Nakai, H.; Klene, M.; Li, X.; Knox, J. E.; Hratchian, H. P.; Cross, J. B.; Bakken, V.; Adamo, C.; Jaramillo, J.; Gomperts, R.; Stratmann, R. E.; Yazyev, O.; Austin, A. J.; Cammi, R.; Pomelli, C.; Ochterski, J. W.; Ayala, P. Y.; Morokuma, K.; Voth, G. A.; Salvador, P.; Dannenberg, J. J.; Zakrzewski, V. G.; Dapprich, S.; Daniels, A. D.; Strain, M. C.; Farkas, O.; Malick, D. K.; Rabuck, A. D.; Raghavachari, K.; Foresman, J. B.; Ortiz, J. V.; Cui, Q.; Baboul, A. G.; Clifford, S.; Cioslowski, J.; Stefanov, B. B.; Liu, G.; Liashenko, A.; Piskorz, P.; Komaromi, I.; Martin, R. L.; Fox, D. J.; Keith, T.; Al-Laham, M. A.; Peng, C. Y.; Nanayakkara, A.; Challacombe, M.; Gill, P. M. W.; Johnson, B.; Chen, W.; Wong, M. W.; Gonzalez, C.; and Pople, J. A. (2004) Gaussian 03, revisison c.02. Gaussian Inc. 